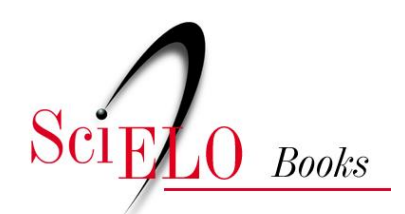

\title{
María Zambrano y la razón poética propuesta de ruptura de paradigmas frente a la educación
}

\author{
Roberto Johan Briones Yela
}

\section{SciELO Books / SciELO Livros / SciELO Libros}

BRIONES YELA, R.J. María Zambrano y la razón poética: propuesta de ruptura de paradigmas frente a la educación. In: IZA VILLACÍS, V.A., ed. Persona, educación y filosofía: reflexiones desde la educación universitaria [online]. Quito: Editorial Abya-Yala, 2018, pp. 45-65. ISBN: 978-9978-10493-4. https://doi.org/10.7476/9789978104934.0004.

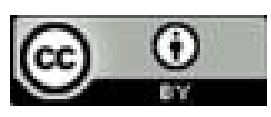

All the contents of this work, except where otherwise noted, is licensed under a Creative Commons Attribution 4.0 International license.

Todo o conteúdo deste trabalho, exceto quando houver ressalva, é publicado sob a licença Creative Commons Atribição 4.0.

Todo el contenido de esta obra, excepto donde se indique lo contrario, está bajo licencia de la licencia Creative Commons Reconocimento 4.0. 


\title{
María Zambrano y la razón poética: propuesta de ruptura de paradigmas frente a la educación
}

\author{
Roberto Johan Briones Yela ${ }^{1}$
}

El conocimiento empieza en el asombro

(Sócrates)

\section{Resumen}

El presente trabajo muestra una breve historia de los modelos educativos actuales y sus raíces -evidenciando los efectos a los que han llevado las teorías "pedagógicas" de la modernidad-, para luego; en un segundo momento, recorrer someramente la historia de las filosofías que aportaron a la formación y construcción del pensamiento de María Zambrano, donde su original aporte a la educación desde la filosofía, intenta abrir un espacio renovador para la educación del siglo XXI.

Desde aquí, se presenta la humanización de la ciencia según la razón poética Zambraniana -eje central del ser de la filósofa-, proponiendo un cambio de paradigmas pedagógicos desde el conoci-

1 Magister en Educación, mención Gerencia. Magister en Filosofía por la Universidad Pontificia Bolivariana, Medellín, Colombia. Candidato a Doctorando en Filosofía UPB, Medellín, Colombia. Docente Pastoral Universitaria, Universidad Politécnica Salesiana, Guayaquil, Ecuador.rbrionesy@ups.edu.ec 
miento de la filosofía vivencial de la autora para alcanzar una actitud filosófica donde prevalezca el pensar antes que el formar.

Palabrasclave: MaríaZambrano, razón poética, modernidad, paradigmas.

\section{Abstract}

The present work shows a brief history of the current educational models and their roots, making clear the effects those who have pedagogical theories of modernity, for then; in a second time, explore briefly the history of the philosophies that contributed to the formation and construction of the thought of María Zambrano, where his original contribution to education from the philosophy, trying to open a space renovator for the education of the century XXI.

From here, the humanization of science according to the poetic reason Zambraniana -central axis of the being of the philosopher-, proposing a change of pedagogical paradigms from the experiential knowledge of the philosophy of the author to achieve a philosophical attitude prevails the thinking before that the form.

Keywords: Maria Zambrano, poetic reason, modernity, paradigms.

\section{Introducción}

La filosofía, como ciencia del amor a la sabiduría ( $\varphi \imath \lambda \varepsilon i v$ : amor y бoфía: sabiduría), siempre se ha caracterizado por ofrecer respuestas. Estas -necesariamente- han surgido de sendos procesos de investigación y búsqueda de la verdad. De esta micro reflexión, es lógico deducir que el tema "educación", siempre estará presente en su continuo peregrinar por el mundo del conocimiento.

Por ello, aunque lo lamenten la ciencia y las ciencias por temas de conveniencias ideológicas, uno de los pilares en la construcción de las sociedades ha sido y es la educación, y esta a su vez, sustentada en la pedagogía que a su vez necesita de la filosofía. 
Por esto, el diálogo filosofía-educación, siempre ha estado presente en la óptica filosófica: desde los egipcios, babilonios y griegos, hasta el mundo moderno de hoy.

Lamentablemente hoy, en un mundo donde se impone el actuar por el pensar -o sin pensar- (Nickerson, 1987, p. 28), el sentir por el ser, y el tener por el trascender, el diálogo se puede considerar -sino roto-, interrumpido.

Surge entonces una necesidad de re-hacer este diálogo, de re-componer aquello que las conveniencias rompieron, generándose un espacio válido para que la filosofía aporte en la construcción de una nueva sociedad desde la transformación de la concepción educativa.

A este punto, es lógico que se comience buscando nuevas propuestas, surgiendo la idea de proponer paradigmas -desde una actitud filosófica como la de María Zambrano y su Razón Poética-, hagan prevalecer el pensar antes que el formar, ${ }^{2}$ enriqueciendo el aprendizaje.

Para alcanzar este fin, el presente trabajo está sustentado en el método documental, instrumento de apoyo que facilita -dentro del proceso de Investigación científica-, el dominio de las técnicas empleadas para el uso de la Bibliografía.

¿De qué manera la actitud filosófica -depositada en la Razón Poética- de María Zambrano podría ser propuesta como paradigma para educar hoy en la universidad?, y ¿por qué la filosofía de María Zambrano y su razón poética?; sencillo, porque en un mundo sin sentido donde hasta lo real, concreto y demostrable hoy es puesto en duda, sirve volver a la poesía como herramienta de ruptura con lo general y relativo.

\section{La historia: sustento de una filosofía pedagógica}

A lo largo de la historia del ser humano, la filosofía ha sido pilar fundamental en la generación y construcción del conocimien-

2 NA: Por formar entiendo; construir, hacer, plasmar. 
to, pues como disciplina nos invita a la reflexión y al pensamiento. Prueba de ello, el sin número de filósofos que hoy vienen reconocidos como padres de la física, la matemática, la biología, la pedagogía y demás. Ello, sin desmerecer el aporte a la misma filosofía. De otro lado, si nos referimos a filosofía de la educación, se puede entender la ciencia donde “...se estudian las características de la perspectiva filosófica como una aproximación filosófica al conocimiento de la educación como disciplina académica" (Amilburu, y García, 2013, p. 9).

Ahora, desde esta premisa, intentar comprender el pensamiento pedagógico o las diferentes corrientes pedagógicas del siglo XIX, es hacer clara referencia a la historia de la educación y su apego a la filosofía.

Haciendo un breve recorrido por esta historia, vemos que el desarrollo del pensamiento pedagógico tiene lugar en Grecia y Roma con figuras conocidas en la filosofía antigua, tales como Demócrito y Quintiliano.

Protágoras, eminente sofista, sostenía que la naturaleza humana, el conocimiento y la experiencia eran los principios de la educación. A esta escuela se le debe el currículo de las llamadas siete artes liberales (el trivium y el cuadrivium), que marcaron el paradigma de la educación superior durante varios siglos y de las cuales, provienen las actuales divisiones entre disciplinas literarias y científicas.

Luego surgió la gran trilogía de hombres que con sus ideas impactaron el mundo: Sócrates -cuyas aulas de clases fueron las plazas de Atenas-, Platón -quien funda una escuela que se mantuvo durante nueve siglos, en los jardines de Academo (Academia de Platón)- y Aristóteles -quien, después de haber sido alumno de Platón durante veinte años, fundó el Liceo o Gimnasio de Atenas en el año 335 a.C.-De hecho, a Aristóteles se lo conoce como el pensador que llegó a estructurar una verdadera "Filosofía de la Educación" y quien, a través del "Liceo", logró sistematizar el conocimiento y generar la investigación de nuevos conocimientos desde la observación y la lógica. 
Aristóteles es considerado el padre del método científico, mismo que aun hoy es empleado por las universidades, valiendo la pena acotar, que en estas instituciones no se otorgaban títulos o grados ni se practicaban exámenes o evaluaciones.

Algunos expertos e historiadores sostienen que la primera universidad se constituyó en Salerno en el siglo XI, pero esta no fue más que una escuela de medicina. La primera universidad realmente fue la de Bolonia, fundada a principios del siglo XII (año 1119), en la cual los estudios sobre leyes tenían mucho prestigio, pero colateralmente se impartían estudios de teología, matemáticas, filosofía, astronomía, medicina y farmacia. Las siguientes universidades en aparecer fueron la de París (1150-1160), Oxford (1167), Valencia (1208), Cambridge (1209), Salamanca (1220) y Padua (1222). Entre las más antiguas también están las de Praga y Viena. Es importante la opinión de Ashby, en cuanto a que "La universidad es la organización social más exitosa que haya podido inventar el hombre en la edad media" (Ashby, 1969, p. 73).

En la evolución y desarrollo de la universidad medieval se polarizaron los modelos hacia dos arquetipos bien definidos, aunque distintos: el modelo de Bolonia y el de París. El primero surgió de los ímpetus estudiantiles que buscaban profesores; ellos participaban directamente en el gobierno y administración universitaria.

El prestigio de Irnerius, ${ }^{3}$ como primer glosador o comentarista del "Código de Justiniano" permite que la fama de Bolonia atraiga muchos estudiantes extranjeros. Luego, Gratianus ${ }^{4}$ funda la ciencia

3 Jurista italiano incorporado a la llamada Escuela de Bolonia, trabó conocimiento de los gramáticos y retóricos de la época y siguió la línea del movimiento medieval de renovación de las artes, que removió los cimientos del conocimiento tradicional del sistema jurídico y del Derecho, al otorgarle autonomía propia y entidad suficiente, separándolo precisamente de la gramática y la retórica que tan bien había llegado a conocer.

4 Monje jurista y maestro de Artes Liberales de Etruria y Bolonia, convirtió, junto al prestigioso Imerio, la Universidad de Bolonia en el centro del estudio del Derecho por excelencia. 
del Derecho Canónico que contribuyó grandemente a acrecentar el prestigio de esta universidad. Bolonia, aunque parezca raro, llegó a poseer en sus aulas hasta diez mil estudiantes en el siglo XII, incluso Dante y Petrarca la visitaban frecuentemente. En esta institución, para ser Rector-Estudiante había que ser clérigo, tener veinticuatro años de edad, estudiar quinto año y vestir traje talar (Ávila, 1997).

La de París, llamada la Gran Universidad Teológica -nacida para prestar servicio a las necesidades de la Iglesia Católica-, era gobernada por los profesores, que formaron una corporación que luchó para defender su autonomía ante el canciller y la autoridad civil. Al Papa se recurría en caso de litigio.

En esta época, se practicaba la libertad de cátedra debido al auge de las discusiones y de la lógica, método impulsado por Pedro Abelardo, eminente Maestro de la universidad, pero las autoridades de la Iglesia Católica presintieron el peligro de esta práctica en contra de sus intereses. No está por demás decir que la Universidad de París recibió la protección de las autoridades eclesiásticas ya que era la fortaleza de fe y de la ortodoxia católica. Por eso, la vigilaban estrictamente y supervisaban su enseñanza y actuación para evitar cualquier desviación. ${ }^{5}$

El modelo de Bolonia fue seguido por Salamanca y por la mayoría de las universidades que se fundaron en Europa meridional. En cambio, el de Paris fue imitado por las instituciones de Europa septentrional (Ávila, 1997, p. 22).

Las universidades de Latinoamérica siguieron el modelo de Salamanca, en la que la participación estudiantil en el gobierno universitario era casi nula. Este diferente origen explica la distinta importancia que, en su vida institucional, le dieron a la participación estudiantil, en especial en el gobierno universitario.

5 Disponible en: https://goo.gl/GGCmez 
Luego, situémonos en el siglo XVII como en un instante histórico en el que aparecen los colegios-internados de los Jesuitas cuya finalidad era ofrecer a la juventud, una vida metódica, lejos de las turbulencias y problemas propios de la época y de la edad.

A pesar de lo aparentemente exitoso de estas experiencias, aparecieron sendos intentos de reformas y/o cambios, desde la crítica a la educación y a los internados, realizados por Comenio, quien postulaba una "escuela única y exigía escolarización a cargo del Estado".

Pero no es sino hasta el siglo XVIII, en el que se da una verdadera inquietud pedagógica: ¿debe el estado encargarse de los sistemas educativos?

Los ideólogos de la Revolución Francesa fueron quienes impusieron a los Estados la obligación de encargarse de esta tarea. Pero debemos tomar en cuenta que dicha revolución, no solo era de carácter práctico, sino fundamentalmente de carácter ideológico, esto buscando cambios desde la transformación del pensamiento. Por tanto, sí existía una demanda social clara en las reflexiones de los intelectuales de la época, acerca de que "es tarea del gobierno promover la instrucción pública, gratuita y obligatoria”, tal como la conocemos ahora.

Destacan los criterios filosóficos de autores como Rousseau (1712), quien insistía en el hecho de que, a los estudiantes, hay que tratarlos como adolescentes más que como adultos en miniatura, y que se debe dar mucha importancia a la personalidad individual. Su más firme seguidor, Johann Pestalozzi (1746), buscaba adaptar el método de enseñanza al desarrollo natural del niño. Para lograrlo, consideraba el desarrollo armonioso de todas las facultades del educando (cabeza, corazón y manos).

Las características de esta escuela estatal eran:

Culminar con el dominio del "arte de la retórica" o el "arte de disertar"; el maestro es quien reina en todo el universo pedagógico, orga-

6 De hecho, Comenio afirmaba que "el fin de la formación del hombre fuese espiritual y civil"; y añadía que "educar es vivir". 
niza la vida y las actividades, vela por el cumplimiento de las reglas y formas de los problemas que se plantean, pero mantiene una actitud distante con los alumnos; el rol del estudiante es pasivo y descuida el pensamiento creativo. La escuela tradicional significa, por encima de todo, método y orden, dándole gran importancia al aprendizaje memorístico, en donde el castigo es una estrategia para la eficacia en el aprendizaje y la disciplina (Palacios, 2010, p. 34).

El siglo XIX fue el período en que los sistemas nacionales de escolarización se organizaron en la mayor parte de las naciones europeas. La educación se centra en la infancia: aparece el "progresismo" como un sistema de enseñanza basado en las necesidades y en las potencialidades de los niños más que en las necesidades de la sociedad. En este período, destacan las influencias de autores como el británico Bertrand Russell (1872), la italiana María Montessori (1870) y el americano John Dewey (1859). El método de Dewey, incluso, ejerció amplia influencia en los sistemas educativos en América Latina, de tal forma que el siglo XIX, estuvo marcado por la expansión de los sistemas educativos de las naciones industrializadas en función de sustentar el modelo capitalista.

De todo lo anterior, se puede inferir que el desarrollo de la universidad, como parte de este existir de la educación, no ha sido un proceso tranquilo ni uniforme, sino lento, irregular y hasta violento. Ella -la universidad- ha sido como ahora, el reflejo de lo que sucede en la sociedad: no es la que moldea a la sociedad sino al revés. Desde esta perspectiva, hay que reconocer el papel fundamental de la filosofía dentro del campo de la ciencia y las ciencias donde hoy, en un mundo sin sentido como afirmaría Wittgenstein (Wittgenstein, 1921), cobra vital importancia para el campo específico de las categorías humanistas.

\section{María Zambrano, la filosofía y su razón poética}

En este entorno (temporal) y con esta visión de educación se encuentra María Zambrano (1904), hija de pedagogos y para quien el hombre, no es simplemente un ser histórico, sino que es un ser destinado a trascender y a trascenderse. Esto -desde su pensamien- 
to- implica que el hombre es un ser en perenne construcción, inacabado que va creándose a medida que va viviendo. De aquí que una de las preocupaciones de Zambrano es "humanizar la historia para lograr que la razón sea una herramienta adecuada para el conocimiento de la realidad y el asumir la libertad mediante el despertar de la conciencia personal” (Fernández Martorell, 2004, p. 7).

Para Zambrano, el hombre está dotado de una sustancia en su interior: el ser. Ese ser son sus sentimientos, sus ideas más profundas; lo más sagrado del yo y de una conciencia. Es innato, “...pues aparece desde el primer día que existimos aún sin ser conscientes. La conciencia se va creando poco a poco en cuanto nos surgen dudas y, a través de estas sustancias, debe buscar su unidad como persona" (Venegas, 2014, p. 90)

Desde esta forma de ver al ser, Zambrano propone su "Razón Poética", que trata de penetrar en los "ínferos del alma para descubrir lo sagrado, que se revela poéticamente y que nace como un método nuevo e idóneo para la consecución del fin propuesto: la creación de la persona individual" (Fernández Martorell, 2004, p. 8).

Pero ¿cómo puede esta filosofía influir en el hecho educativo?, ¿qué implicaciones tiene esta influencia en el hombre que busca educarse? Intentando construir un criterio de juicio o aporte, hay que hablar de ideologías.

Cuando aparece la modernidad como ideología, el mundo se rinde a sus pies alabando el desarrollo de procesos industriales donde; a perjuicio de la realidad humana, se comienza a priorizar el capital por sobre lo social. Vivir sin principios trascendentes como ordenamiento para la sociedad, buscar lo inmediato, rápido o inmanente, absolutizar la razón y el progreso por sobre todas las cosas y finalmente romper; desde la conciencia, con el pasado, fueron los ideales que; cual caballo de batalla, esgrimieron los adeptos y defensores de esta visión.

En un segundo momento; luego de hacer madurar en las gentes la modernidad, aparece "algo" llamado posmodernidad. 


\section{4}

¿Qué se puede decir de esta ideología, fenómeno o categoría social?, veamos lo que Harvey $(1989)^{7}$ nos dice al respecto:

Existe quizás un cierto consenso según el cual el típico artefacto posmodernista es leve, auto-irónico y hasta esquizoide; y reacciona a la autonomía austera del alto modernismo adoptando de manera imprudente el lenguaje del comercio y de la mercancía. Su posición con respecto a la tradición cultural es la de un pastiche irreverente, y su artificial superficialidad socava toda solemnidad metafísica, en ocasiones mediante una estética brutal de suciedad y shock (Harvey, 1998, p. 42).

Es entonces, bastante difícil encontrar acuerdos acerca de qué se entiende por este término, excepto quizás, en que el posmodernismo representa cierto tipo de reacción o distancia respecto del modernismo.

En arquitectura, ${ }^{8}$ por ejemplo y según los redactores de la revista "Precis" (1987, pp. 7-24), el posmodernismo es una "reacción legítima a la monotonía de la concepción modernista del mundo" (AA.VV., 1987).

El modernismo universal, concebido por lo general como positivista, tecnocéntrico y racionalista, ha sido identificado con la creencia en el progreso lineal, las verdades absolutas, la planificación racional de regímenes sociales ideales y la uniformización del conocimiento y la producción (AA.VV., 1987, p. 6).

Eagleton" (1987) al respecto afirma: "El posmodernismo señala la muerte de estos "meta-relatos cuya función secretamente terrorista era fundar y legitimar la ilusión de una historia humana universal” (Harvey, 1998, p. 18).

La filosofía también tiene mucho que aclarar sobre el término posmodernidad, por lo que Nicolás Casullo ${ }^{10}$ (1995) ya presagia una

7 David Harvey (1935), reconocido geógrafo y teórico social británico, catedrático de Antropología y Geografía en la City University of New York.

8 Me valgo de este análisis para ilustrar lo intromisivo del termino en las ciencias.

9 Terry Eagleton (1943), inglés, crítico literario y de la cultura británica.

10 Nicolás Casullo (1944), filósofo y escritor argentino, profesor titular, director de posgrado e investigador en la Facultad de Ciencias Sociales de la 
"problemática anticipativa" al hecho de presentar un escrito donde se aborde el debate modernidad-posmodernidad.

Finalmente, en su texto "El debate modernidad-posmodernidad", intenta demostrar la sustentabilidad -forzada- del término en las ciencias y la sociedad. De hecho, afirma que:

...la noción de posmodernidad surgida del campo del arte y de cierta acumulación de teorías críticas con intencionalidad disruptiva frente a la razón ilustrada, ya sea por derecha o por izquierda, aspiraba a construir un relato "post» que centrase las muchas cuestiones expresivas, reflexivas y políticas en juego. Lo posmoderno, ambicionaba ser la clave de un tiempo, aunque fuese desde la reyerta (Casullo, 2004, p. 5).

El ser humano visto como objeto, máquina o "cosa”, al cual se le quitan las utopías, la personalidad propia y original, dejando seres que solo buscan lo inmediato, el culto a sí mismos, el consumismo y-por supuesto- vivir la vida.

Estas son solo algunas de las características de lo que implicó el aterrizaje de estas ideologías en el hombre, reafirmando el hecho de que la palabra "posmoderno" -y por ende lo posmoderno con todo lo que implica- existe dentro de las ciencias, así sea a la fuerza. Ahora, que la filosofía debata si ello es verdadero o no, no creo deba ser tema de este trabajo que apunta hacia otros horizontes, por ello se deja este apartado y se retoma la temática central de este escrito: filosofía y educación.

Durante muchos siglos, la filosofía ha dejado su papel de amante de la sabiduría para convertirse en constructora de sustentos para las ideologías imperantes. Vemos que, del concepto socrático de filosofía como sentido de la ética, la filosofía ha pasado a ser sentido sin sentido en ocasiones y, en otras, sentido de estructuras que bus-

Universidad de Buenos Aires y en la Universidad Nacional de Quilmes. 
can perennizarse. Atrás quedaron los días en que filosofar implicaba la búsqueda constante del ápeiron y sus posibles significados.

Por ello se intenta sustentar una vuelta a ese sentido originario de la filosofía, y esto, necesariamente se vuelve útil, en el proyecto de ir construyendo al ser desde la búsqueda de la verdad mediante el amor a la sabiduría y el sentido de la vida.

Ante ello, desde la filosofía -y como búsqueda de aterrizar un modelo distinto de pensar la educación-, se toma una frase de Sánchez-Gey: "se publica para vivir"," al respecto de sus ideas frente al pensamiento de los escritos de la filósofa veleña María Zambrano. A esto está llamado el filósofo realmente: escribir para vivir, para sentirse vivo.

Por supuesto esta visión de vida es muy diferente a la que hoy se propugna en las aulas - por mencionar un ambiente educativo- de la academia, donde lo importante es ideologizar al ser para el profesionalismo, de manera que sustente y promueva modas sociales materialistas y capitalistas.

Frente a esto, las preguntas que surgen entonces son: ¿cómo, de qué manera, y cuánto aporta la Razón Poética de María Zambrano al pensamiento, a la sociedad y a la educación...?

Con una amplia visión filosófico-pedagógica, María Zambrano, afirma que la educación debe guiar "el deseo que todo ser humano tiene de abrirse paso a la esperanza”, de aquí que la atención debe estar centrada en el acto intencional como creador, mismo que nos llevará a reconocer el fin que proporciona sentido a la vida" (Casado \& Sánchez-Gey, 2011, p. 3).

Esta visión ha hecho entrever, desde nuestra perspectiva, los trazos filosóficos de María Zambrano, donde el hombre y lo divino van

11 Nota tomada del módulo "Valor y valoración. La persona en filósofos españoles contemporáneos”, Dra. Juana Sánchez-Gey, UPB, Colombia, 2014. 
de la mano sin necesidad de juicios racionales que opaquen el discernimiento sobre ellos: este es el sustento de la Razón Poética zambraniana.

Estamos frente a la ruptura -filosófica- entre el pensamiento del maestro (Ortega) y la discípula (Zambrano).

Ortega nos presenta su Razón Vital, la cual; siguiendo un recorrido sintético para este trabajo ${ }^{12}$, tiene su base inicial en las discusiones sobre el ser y el pensar de Descartes y su cogito ergo sum, elemento esencial del racionalismo occidental.

Si nos remitimos a la tercera parte del "Discurso del Método", Descartes cree que en general conviene proponerse metas realistas y actuar resueltamente, pero en lo cotidiano -en cambio- hay que adaptarse al entorno sin lo cual la vida se llena de conflictos, que irremediablemente privarán de las condiciones mínimas para investigar (Quintás, 1981, p. 137).

Mi segunda máxima era ser en mis acciones lo más firme y lo más resuelto que pudiese, y no seguir con menos constancia las opiniones más dudosas, una vez que me hubiese determinado, que si hubiesen sido muy seguras (Descartes, 2004).

La Razón Vital Orteguiana, más tarde se nutrirá del pensamiento existencialista de Kierkegaard y de Sartre, quienes postulaban grosso modo que la existencia precede la esencia, es decir que no es la naturaleza humana la que nos determina, sino que son nuestros actos los que determinan quiénes somos y el significado de nuestras vidas.

De hecho, Kierkegaard sostenía que el bien más alto para el individuo es encontrar su propia vocación: "Debo encontrar una verdad que sea verdadera para mí, una idea por la que pueda vivir o morir" (Svensson, 2013, p. 10). Su pensar, se centra en el "individuo

12 NA: Por motivo de espacios y tiempos, se resume un recorrido extenso en pocas líneas, se pide disculpa por esta "herejía" histórica-filosófica. 
existente", base de la experiencia personal y del actuar de acuerdo con convicciones propias; aspecto esencial para alcanzar la verdad.

Sartre de su parte pensaba que en el ser humano la existencia precede a la esencia, por un lado; pero, por otro lado, rechaza en su libro "El ser y la nada" (1943), la nada como algo "irrealizante"; o sea la destrucción de lo ya dado para crear nuevas realidades. Luego, cada uno de nosotros, está obligado -por compromisos existenciales- a ayudar al otro (sentido de la otredad) sin lo cual la vida se entiende como vacía, sin sentido. Incluso, se mostraba escéptico frente a la idea de que el hombre pudiese alcanzar algún tipo de logro personal como re-encuentro con el ser, del cual habla Heidegger (1927), y más vale creía firmemente que el hombre es una criatura obsesionada y angustiada por la idea de completarse (Paul, 1984)

Ortega se nutre de estas vastas corrientes de pensamientos y de autores que repensaron dichos pensamientos (Jaspers, Unamuno, Beauvoir, Camus, Locke, Hume, Spinoza, etcétera), para proponer una "razón vital", misma que integra todas las exigencias de la vida, nos enseña la primacía de esta y sus categorías fundamentales, no prescindiendo de las características de cada cultura o sujeto, sino haciendo compatible la racionalidad con la vida.

El hombre -según Ortega y Gasset- es el problema de la vida, entendiendo por vida lo concreto, incomparable, único:

...la vida es lo individual; es decir, yo en el mundo; y ese mundo no es propiamente una cosa o una suma de ellas, sino un escenario, porque la vida es tragedia o drama, algo que el hombre hace y le pasa con las cosas. Vivir es tratar con el mundo, dirigirse a él, actuar en él, ocuparse de él. En otros términos, la realidad circundante 'forma la otra mitad de mi persona'. Y la reimpresión de lo circundante es el destino radical y concreto de la persona humana (Ortega y Gasset, 1966, p. 47).

Ortega definía al hombre como un ser compuesto de realidades circunstanciales creadas por la confusión del pensar y en el sedentarismo, como fuente inspiradora de las culturas neo-pensantes 
-los jóvenes desde nuestro entender- incapaces de olvidar la rigidez que usurpa a la sabiduría de su mente.

Así habla Zambrano del centro del pensamiento de su maestro:

Ortega, todo lo convertía en horizonte, un modo de salvar las circunstancias esencialmente filosófico (...), donde una roca, vino a ser la resistencia prometedora donde se encierra algo que tal vez sea lo más precioso. La resistencia es la nota propia de la realidad en la filosofía de Ortega, y ¿la vida, la realidad radical? (Zambrano, 2011, p. 180).

La razón vital que plantea Ortega sustituye la razón pura cartesiana de la tradición filosófica.

Se puede notar la influencia de Ortega y Gasset, sobre el pensamiento de María Zambrano, pues este veía la vida como realidad radical, como fuerza en sentido dinámico y relacional y el futuro como perspectiva fundamental para "entender la vida" (Brioso, 2005, p. 57).

La razón vital de Ortega quiso superar; integrándolos, el racionalismo y el vitalismo -o el existencialismo-, esto a partir de la evidencia de que el hombre no podía considerarse independiente de sus circunstancias y de que la vida era en sí la única realidad radical (Maillard, 2005, p. 21), desde aquí, la razón habría de dejar de construir en el aire, pues como afirma Ortega, “...no podía ser un constructo abstracto sino un modo de ser del hombre en su vida, en su historia" (Brioso, 2005, p. 61)

Por esto, más que frente a una filosofa racional o existencial, nos encontramos frente a una pensadora que trabaja muchas de sus obras desde el punto de vista filosófico-pedagógico, rompiendo con la construcción de tratados de filosofía heredados por sus formadores, y orientando -desde su amplia visión y conocimiento de la misma- al ser hacia lo poético, categoría trascendental en la que se alineó definitivamente en la realidad, como gesto humano y personal, que muy pronto se verá en su obra bajo el epígrafe de "Razón Poética". 
María Zambrano aporta a la filosofía ese humanismo que faltó; en ocasiones -y pecando de herejía-, a algunos pensadores griegos, romanos y posteriormente europeos. Su visión de "razón compasiva", devela su inclinación natural por el ser, por la persona y los sufrimientos a los que ésta está expuesta.

Filosóficamente hablando, María Zambrano es hija de su época, pero no sólo a los filósofos debe su particular forma de pensar, sino también a autores que pertenecen al ámbito de la psicología (Jung), de la mística (Sn. Juan de la Cruz) y de la antropología religiosa (Eliade, Corbin), de esto último, se hace relación en la temática tomada por la Dra. Sánchez-Gey, cuando expone a la Filosofía de la Religión, como explicación de Zambrano al hecho religioso: una filosofía que abrace la religión y una razón más compasiva (Brioso, 2005, p. 75).

Acerca de la educación y su estrecha relación con la filosofía, María Zambrano entiende que la educación es como la comunicación entre un maestro y un discípulo, y que esta relación requiere dos momentos: habla y escucha.

En el vacío del aula sucede algo; algo que va más allá de lo que se aprende materialmente en ellas. Muchos de los que por ellas han pasado tal vez no adquirieron tantos conocimientos como fuera menester. Pero les sucedió algo en la frecuentación de las aulas; algo esencial para ser hombre se les enseñó en ellas: a oír, a escuchar, a atender, a dejar que el tiempo pase sin darse cuenta queriendo entender algo, abrirse al pensamiento que busca la verdad (Zambrano, 2007).

La última afirmación de la filósofa es -hablando de educación-, un llamado a hacer filosofía: “...abrirse al pensamiento que busca la verdad”, pero no solo eso, el entero párrafo es muestra de su pensar filosófico desde la verdad del poeta: oír, escuchar y atender.

Dentro de esta propuesta de nuevo humanismo desde la educación, nos encontramos con su idea de "humanización de la historia”, entendiendo, como afirma Sánchez-Gey, que: 
...el humanismo no es solo acercamiento al hombre concreto en su cotidianeidad, sino que supone la defensa de la trascendencia, vivir la esperanza de saber que el ser humano es educable, que puede crear un mundo mejor. Pues la esperanza en Zambrano es más que un sentir, constituye el nervio vital del ser humano (Venegas, 2014, p. 94).

Otra categoría importante en la visión educativa zambraniana es la atención.

Sobre ello afirma:

...la primera acción será una especie de inhibición, paradójicamente, una retirada del propio sujeto para permitir que la realidad, ella, se manifieste. $Y$ en ese punto la atención ha de hacer una limpieza de la mente y del ánimo. Ha de llevar la atención al sujeto al límite de la ignorancia, por no decir de la inocencia (Zambrano, 2007).

La atención -actividad propia del vivir y obrar del hombre-, debe ser educada para poder obtener el mejor provecho. Una persona educada es una persona que siempre estará en sentido de atención, de escucha; es una persona que cuida su atención y sabe elegir lo que atiende.

María Zambrano entiende el proceso de atención, como un atributo de la conciencia humana, y ello nos abre a la conciencia, a conocer quién es el otro. De ahí la importancia del tutor o guía, quien debe desde la intención del enseñar a pensar-, lograr unificar la atención del tutoriado hacia lo que verdaderamente debe ser importante para él.

La atención, como tal vez todo lo que podamos distinguir en la psique y en la persona humana, se da en círculos concéntricos. Se diría que a mayor unidad de la persona - ya que el oficio de la llamada persona es la de unificar-, cuanto más lograda sea la unidad de la persona, la atención se da en mayor número de círculos (Zambrano, 2007).

Finalmente, la última categoría tratada por Zambrano dentro del acto educativo, es la libertad, categoría netamente filosófica que en nuestra autora implica la capacidad humana de reconocer el fin que proporciona el sentido a la vida. 
Hablar de libertad en María Zambrano es dedicar unos párrafos a su vida, que, desde el exilio, continuó sobrellevando en aras de promocionar la verdad y su deseo de una España libre, autónoma y pensante.

Al respecto Sánchez-Gey nos dice que, para Zambrano, la libertad "...es comprender este sentido [en que] la persona ha de conocerse bien a sí misma y ser capaz de renunciar a todo lo que la encadena para hacer posible vivir la libertad" (Venegas, 2014, p. 97).

Para la filósofa, "la ética es una libertad creadora, que surge como potencia y posibilidad de creación, como esfera de una existencia personal, como condición del espíritu" (Venegas, 2014, p. 97).

Vale la pena acotar que, según Zambrano, esta realidad para ser aprehendida, requiere de un método. Aquí entra en juego lo antes expuesto sobre su visión pedagógica: Escucha, atención y libertad. Sólo así, es posible despertar el "poder latente" en el fondo de la naturaleza humana y en su caso, expresarlo. Puesto que lo que se pretende es lograr la transformación interior, el saber teórico debe estar fusionado a la práctica, no puede darse lo uno sin lo otro como base experiencial del sujeto.

Su obra, está dedicada a presentar la relación entre el Hombre y lo Divino, desde algunas aristas: Dios, la pedagogía, la estética, la misericordia, entre otros. El drama de los intelectuales en España, las agonías de Europa, el conocimiento del alma, la persona y la democracia, forman parte de una vastedad de obras, en las que la palabra se encarna en la imagen y la razón, fertiliza en el símbolo.

\section{Conclusiones}

La filosofía se ubica entre las ciencias de lo social u orientadas a lo social, desde que genera en el ser preguntas sobre sí mismo y sobre su relación con el otro.

Desde aquí se puede comprender que el hecho educativo es necesariamente parte fundamental de su ser "ciencia", de su construir "sociedades". La centralidad del discurso filosófico, entonces, 
debe ser orientado no solo a la persona en sí, sino a su formación desde la dignidad, la esperanza y la forma en cómo hoy llegamos -a pesar de la globalización y los demás fenómenos sociales que inhiben al hombre de cuestionarse sobre sí mismo-, a entender la educación en vista del aprendizaje.

Es conveniente hacer caer en la cuenta de que cuando se habla de aprendizaje, se piensa más allá de innovaciones en el ámbito de estrategias metodológicas, didácticas o multimediales. ${ }^{13}$

Por aprendizaje entendemos aquella herramienta olvidada que debe partir de un por qué, para llegar a un para qué. En esta línea, María Zambrano abre las puertas para que, desde la filosofía, nazca nuevamente un concepto de educación sin ataduras capitalistas, ideologías racionales o existenciales ni visiones industriales profesionalizantes.

Un porqué como respuesta de sentido a lo que hago en el presente: elegir una carrera, prepararme no solo profesionalmente sino ideológicamente; y un para qué desde donde, como la visión del poeta heideggeriano, el hombre entienda que debe construirse como ser, antes de construirse como profesional, que luego debe ser, antes que parecer, $y$ finalmente vivir antes que tener.

Por ello, la filosofía debe convertirse en guardiana y garante de la construcción de una sociedad que piense. Este era el "Sistema", -si se lo puede llamar así- que encontramos, desde nuestra lógica, en María Zambrano: la filosofía como una forma de vivir y de pensar, esto necesariamente influye en la educación, de la cual nace el sentido del educador/maestro (vocación zambraniana), quien debe postular -para poder formar-, su apego a la poesía, pues "es indu-

13 De hecho, existen aún autores actuales en el ámbito educativo (Barriga, Hernández, entre otros), que continúan queriendo sustentar la educación en interpretaciones constructivistas o conductistas, léase "Estrategias docentes para un aprendizaje significativo”, McGraw Hill, México (1999). 
dable que el camino por el que logramos la respuesta es una salida" (Heidegger, 1992) y “...la poesía misma hace posible el lenguaje”.

Hace falta un mayor número de autores que enfoquen su visión filosófica en el ser humano de manera holística pues la misma ciencia (filosófica) y las ciencias, hoy buscan una mayor implicación de ese género.

Para cambiar al hombre hay que cambiar la manera de formar a este hombre. El llamado, entonces, es a romper paradigmas: educativos, de aprendizaje, ideológicos, antropológicos y, por supuesto, filosóficos. Hoy la filosofía se ha quedado en analizar e interpretar aquellos problemas que nada tiene que ver con la perdida de humanidad del ser. La razón poética zambraniana, entonces, vista como un paradigma frente a paradigmas, como una espada frente a espadas.

Desde aquí se abren puertas a aquellas personas que; como María Zambrano, intentan crear en esta ciencia del amor a la sabiduría, conciencia social orientada al ser, fin primero y último de la creación.

\section{Bibliografía}

AA.VV. (1987). Estilos e ideas posmodernas. PRECIS, 7-24.

Amilburu, M. \&. García, J. (2013). Filosofía de la educación, cuestiones fundamentales de ayer y de hoy. Revista Complutense de Educación, 229-233. Ashby, H. (1969). La Universidad y los académicos. Caracas: Monte Ávila Editor. Ávila, F. (1997). La Universidad de Alicante heredera de la Universidad de Orihuela. Salamanca: Serial OnLine.

Brioso, J. (Enero de 2005). Ortega-Marañón, Fundación José Ortega y Gasset-Gregorio Marañon. Revista Circunstancia. Disponible en: https://goo.gl/vKrh9y

Casado, A., \& Sánchez-Gey, J. (2011). María Zambrano, Filosofía y Educación (Manuscritos). Alicante: Ed. Club Universitario.

Casullo, N. e. (1995). El debate modernidad-posmodernidad. Buenos Aires: Ed. Claretiana.

Fernández Martorell, C. (2004). María Zambrano: entre la razón, la poesía y el exilio. Barcelona: Ediciones de Intervención Cultural-Montesinos. 
Harvey, D. (1998). La condición de la posmodernidad. Buenos Aires: Biblioteca de Comunicación, Cultura y Medios-FLACSO.

Heidegger, M. (1927). Ser y Tiempo. Editorial Fondo de Cultura Económica, México, 1951. Traducción de José Gaos/Editorial Universitaria, Santiago de Chile, 1997. Traducción de Jorge Rivera Cruchaga Editorial Trotta, Madrid, 2003 (reproduce la versión publicada por la Editorial Universitaria de Santiago de Chile).

Maillard, C. (10 de octubre de 2005). Emakumeak.org. Disponible en: https://goo.gl/M8ShBF

Nickerson, R. S. (1987). Enseñar a pensar. Barcelona: Ediciones Paidós.

Ortega y Gasset, J. (1966). Meditaciones del Quijote. Madrid: Revista de Occidente.

Palacios, J. (2010). La cuestión escolar: críticas y alternativas. Competencias para la Educación, 34-45.

Paul, S. (1984). El ser y la nada. Madrid: Alianza Editorial SA.

Quintás, G. (. (1981). Discurso del Método (Tercera Parte). Madrid: Alfaguara.

Svensson, M. (2013). El pensamiento de Søren Kierkegaard: Polemizar, aclarar, edificar. Barcelona: Editorial Clie.

Venegas, J. (2014). La educación en María Zambrano: su reflexión sobre la persona. La educación en María Zambrano: su reflexión sobre la persona (pp. 90-99). Madrid: Seminario María Zambrano.

Wittgenstein, L. (1921). Tractatus logico-philosophicus. Austria: Harcourt.

Zambrano, M. (2007). Filosofía y Educación: manuscritos. Madrid. (2011). Escritos sobre Ortega. Madrid: Trotta. 